\title{
ТЕОРЕТИЧЕСКИЕ АСПЕКТЫ ПРОСТРАНСТВЕННОЙ ОРГАНИЗАЦИИ ТЕРРИТОРИИ
}

\section{Кристина Рудольфовна Меркурьева}

Тюменский индустриальный университет, 625000, Россия, г. Тюмень, ул. Володарского, 38, аспирант, тел. (922)260-85-91, e-mail: k_r_merkurieva@mail.ru

\section{Александр Викторович Кряхтунов}

Тюменский индустриальный университет, 625000, Россия, г. Тюмень, ул. Володарского, 38, кандидат экономических наук, доцент кафедры геодезии и кадастровой деятельности, тел. (982)786-48-26, e-mail: krjakhtunovav@tyuiu.ru

В статье рассматривается актуальный вопрос по формированию и развитию пространственной организации территории с целью создания комфортной среды жизнедеятельности и жизнеобеспечения. Авторы приводят теоретические положения относительно создания и развития пространственных систем. Авторами раскрываются особенности осуществления градостроительной деятельности как динамичной системы. В результате авторы выделяют важнейшие аспекты, согласно которым возможно устойчивое развитие пространственных систем.

Ключевые слова: организация территории, пространственная система, градостроительная деятельность, планирование, развитие, планировочная документация, градостроительное зонирование, управление территориями

\section{THEORETICAL ASPECTS OF SPATIAL ORGANIZATION OF THE TERRITORY}

\section{Kristina R. Merkurieva}

Tyumen Industrial University, 38, Volodarskogo St., Tyumen, 625000, Russia, Ph. D. Student, phone: (922)260-85-91, e-mail: k_r_merkurieva@mail.ru

\section{Alexander V. Kryaktunov}

Tyumen Industrial University, 38, Volodarskogo St., Tyumen, 625000, Russia, Ph. D., Associate Professor, Department of Geodesy and Cadastral Activity, phone: (982)786-48-26, e-mail:krjakhtunovav@tyuiu.ru

The article deals with the current issue of formation and development of the spatial organization of the territory in order to create a comfortable environment for life and life support. The authors present theoretical propositions concerning the creation and development of spatial systems. The authors reveal the features of urban development as a dynamic system. As a result, the authors highlight the most important aspects according to which the sustainable development of spatial systems is possible.

Keywords: the organization of the territory, of the spatial system, urban planning, planning, development of planning documentation, town-planning zoning, territorial management

Человечество определяет Землю как важнейший объект материального мира. Земля характеризуется совокупностью свойств: обладает свойством территории, то есть является пространственным базисом для размещения 
объектов, при этом одновременно являясь пространственным базисом для природных объектов (лесов, вод, растительности и т.д.), а также представляет собой часть окружающей природной среды. Свойства Земли формируют ее как определенную среду для проживания человека, которая представляет собой сложную систему.

Для обозначения территории, в отношении которой требуется проведение пространственной организации, необходимо ввести термин «пространственная система». Под пространственными системами следует понимать упорядоченную и территориально структурированную, не однородную среду жизнедеятельности человека, различающуюся по величине территорий, функциональному назначению, характеру прав владения, пользования и распоряжения, а также имеющую информационную, культурную и экологическую ценность. Такие системы требуют непрерывного и динамичного развития для успешного построения городского пространства [2].

Пространственная система формируется посредством осуществления градостроительной деятельности.

Под градостроительной деятельностью будем понимать действия со стороны субъектов данной деятельности с целью реализации градостроительного развития урбанизированной территории, в процессе которых происходит определение вида разрешенного использования выбранной территории, осуществляется проектирование, строительство и реконструкция объектов капитального строительства, основанное на природных, экологических, историко-культурных особенностей пространственной системы [3].В качестве субъектов градостроительной деятельности выступают физические и юридические лица, органы местного самоуправления и государственные органы.

Градостроительная деятельность осуществляется за счет системы ее элементов (рис. 1) [1].

Важно отметить, что градостроительная деятельность отличается плановым характером. Это отражается в подготовке документов территориального планирования, градостроительной документации по планировке территории и документации градостроительного зонирования [6]. Указанные выше документы формируют целостную систему градостроительного планирования, служащей основой для управления развитием территории.

Комплекс документов, подготовленный в результате осуществления градостроительной деятельности, играет ключевую роль в формировании инвестиционной привлекательности территории [5]. Благодаря открытости и прозрачности принятых градостроительных решений, потенциальный инвестор в праве рассмотреть и принять участие в создании и развитии пространственной системы.

Градостроительная документация представляет собой динамичную систему, так как актуализируется, учитывая планы и программы социально-экономического развития территории, таким образом, обеспечивая сбалансированное формирование пространственной системы, с учетом социально-экономической, инфраструктурной, жилищной, рекреационной и иной направленности [4]. 


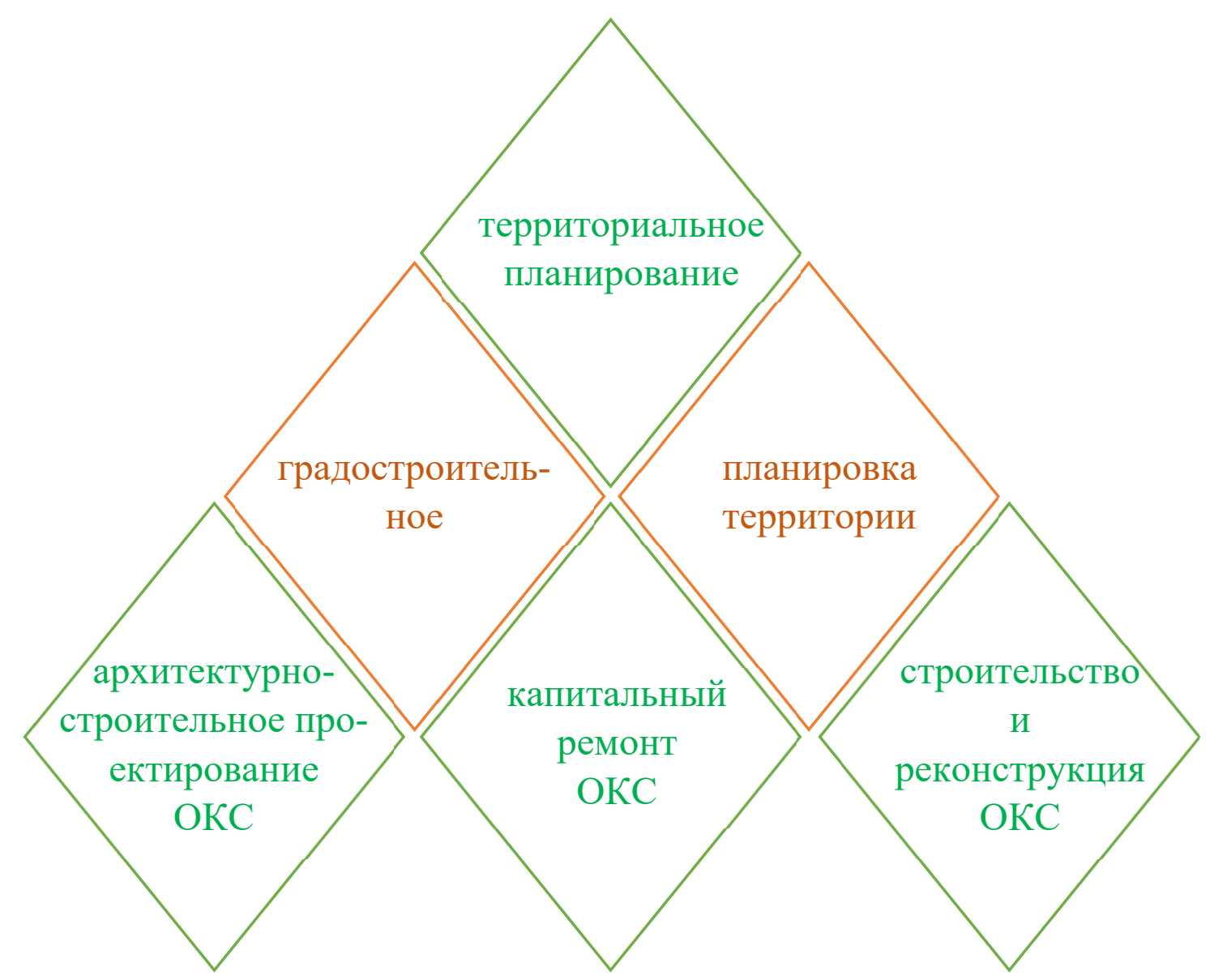

Рис. 1. Компоненты градостроительной деятельности

Важным аспектом формирования пространственной организации территории является неразрывный процесс анализа и обработки пространственных данных с осуществлением градостроительной деятельности. Таким образом, информационное обеспечение занимает основополагающее положение в осуществлении градостроительной деятельности.

Осуществление градостроительной деятельности происходит в определенной этапности и охватывает три крупные сферы (рис. 2) [7].

Сфера планирования включает в себя мероприятия по разработке материалов по развитию пространственной системы на долгосрочную перспективу. Является важной составляющей информационной обеспеченности и способствует принятию обоснованных, надежных и долгосрочных архитектурных и планировочных решений.

Сфера проектирования включает в себя мероприятия по разработке материалов, которые содержат конкретные проектные решения для развития пространственной системы. Основная задача состоит в выявлении оптимального пути разрешения выявленной проблемы в виде соответствующего проектного решения. Основная функция - согласно конструктивному прогнозу развития территории предложить средства реализации. 


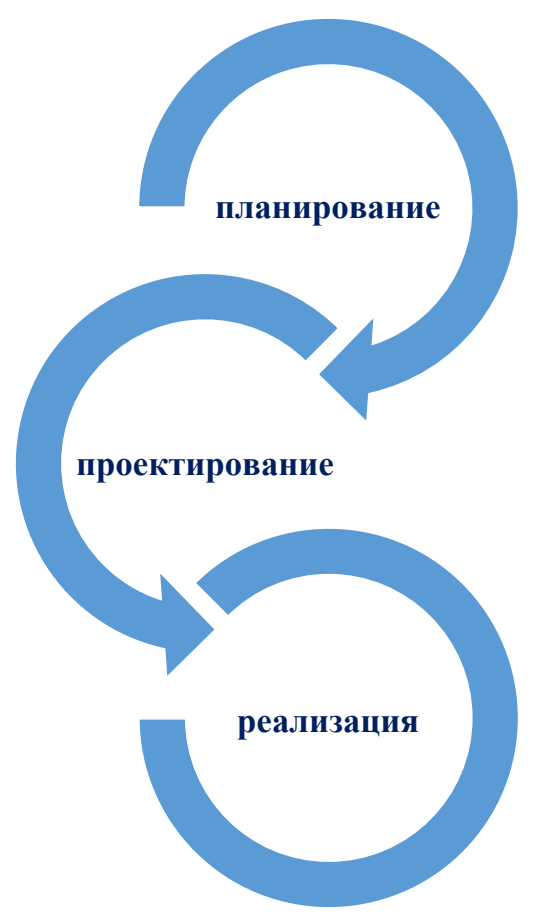

Рис. 2. Сферы формирования пространственной системы

Сфера реализации включает в себя мероприятия по воплощению и претворению материалов сферы планирования и проектирования в натуру. Важность данной сферы заключается в полноте и последовательности осуществления политики в области градостроительной деятельности.

Таким образом, следует отметить важность и необходимость осуществления градостроительной деятельности в рамках пространственной организации территории. Комплекс документов территориального планирования, градостроительного зонирования и планировки территории служит важнейшим инструментом создания комфортной городской среды.

Устойчивое развитие пространственных систем, ее инвестиционная привлекательность складываются в процессе грамотного планирования, проектирования и реализации проектных решений в рамках последовательного и планомерного управления территорией.

\section{БИБЛИОГРАФИЧЕСКИЙ СПИСОК}

1. Груздев В. М. Территориальное планирование. Теоретические аспекты и методология пространственной организации территории : учеб. пособие для вузов. - Н. Новгород : ННГАСУ, 2014. - 146 c.

2. Городков А. В., Федосова С. И. Основы территориально-пространственного развития городов : учеб. пособие. - Брянск : Брян. гос. инженер.-технол. акад., 2009. - 326 с.

3. Merkuryeva K., Kryakhtunov A. Theoretical foundations of the impact of documentation on urbanization and territory development // E3S Web of Conferences «Topical Problems of Green Architecture, Civil and Enviromental Engineering 2019 (TPACEE 2019)» - 2020. - Vol. 164. C. 11031-1-11031-7. 
4. Меркурьева К. Р., Кряхтунов А. В. Научно-теоретические основы подготовки планировочной документации // Актуальные проблемы геодезии, кадастра, рационального землеи природопользования : материалы II Международной научно-практической конференции : сб. трудов конференции в 2 т. (23 ноября 2018 г.) / под ред. А.М. Олейника, М. А. Подковыровой. - Тюмень : ТИУ, 2019. Т. 2. - С. 37-43.

5. Кряхтунов А. В., Черных Е. Г., Богданова О. В. Правовые основы управления развитием урбанизированных территорий : учеб. пособие. - Тюмень : ТИУ, 2020. Т. 2. - 80 с.

6. Пелымская О. В., Черных Е. Г., Кряхтунов А. В. Территориальное планирование муниципального образования : научное издание. - Тюмень : ТИУ, 2017. - 82 с.

7. Авдотьин Л. Н., Лежава И. Г., Смоляр И. М. Градостроительное проектирование : учебник для вузов. - Москва : Стройиздат, 1989. - 432 с.

(C) К. Р. Меркурьева, А. В. Кряхтунов, 2021 